\title{
NON-AGENDA
}

With the view of causing an increase to take place in the mass of national wealth, or with a view to increase of the means either of subsistence or enjoyment, without some special reason, the general rule is, that nothing ought to be done or attempted by government. The motto, or watchword of government, on these occasions, ought to be - Be quiet... Whatever measures, therefore, cannot be justified as exceptions to that rule, may be considered as non-agenda on the part of government.

—Jeremy Bentham (c.1801)

\section{Cyberspace: Public Space or Pub Space?}

\section{Michael Warby}

We may presume that politicians understand pubs. Pubs are basically places for adults, places it is difficult to go to accidentally. Most parents are not happy for children to go there unsupervised. It is illegal for pubs to serve minors. Lots of indulgences go on in pubs. You choose to go there and you can always walk away. Pubs are privately-owned public places. We accept that, while publicans are responsible for whether or not minors are served, their responsibility for what adults do in their pub is limited. They are barred from serving intoxicated people, but apart from things like not serving minors (and repeated convictions for unsupervised minors can lead to loss of licence), there is a limit to pubspecific regulations: most of what goes on is covered by general laws.

We also understand that it would be quite unreasonable to make publicans responsible for all the actions of adults in their facilities. They have no obligation under statute law if people drive off under the influence (though a recent Queensland Supreme Court case suggests some common law duty of care may apply - see Hoyne, 1998). They are not responsible if dodgy deals are done in corners or for the sex in the upstairs room. They are not required to keep records of all comings and goings, to track what people bring in and leave with. We understand that, when supervised, children can be fine in pubs there are often video games to play, conversation, soft drinks to consume. But even our politicians understand that you cannot turn pubs into cheap child-

Michael Warby is Editor of IPA Review. 
minding services without destroying their nature as venues predominantly for adults.

Since politicians understand pubs, they are not about to pass laws to require publicans keep accessible-within-24-hours records of all comings and goings, to police all transactions that take place in their pubs, to police the drink-driving laws, to function as cheap child-minding centres. Because politicians understand pubs, they understand how unreasonable such requirements are, how they would kill off pubs. They understand this even though some of the customers of pubs will, under the influence of what they consumed there (even if they have not reached the point of intoxication such that common law duty of care or the appropriate statutory requirement not to sell them further alcohol applies), go off and kill or harm themselves and other people. But that is understood to be generally the responsibility of adult customers, not the publican.

Politicians also understand phone networks. They understand that Telstra and other phone companies are not responsible for how people use their phones. They are not responsible for dirty phone calls, for abuse, for the spreading of slander, for the undertaking of criminal deals. They understand that the content of the millions and millions of conversations the means for which phone companies provide daily are not, and ought not be, the companies' concern.

Politicians understand postal services. They understand that the Post Office is not responsible for what people send through the Post, for the purposes people put the postal service too, some of which will involve illegal action. Once again, the sheer scale of the operation - even apart from the issues of personal liberty involved - makes any idea of such obligation patent nonsense.

Politicians understand that phone companies, courier services and the Post Office are only service providers, and are not responsible for how adults choose to use their services, though it is illegal to use those services in dangerous ways or for specifically prohibited uses. But those requirements are typically placed on the users of the services, not the providers. Politicians understand that pubs ought not be regulated so as to make them cheap child-minding services.

Politicians understand these things because they grew up with pubs, with phone companies, with the Post Office. Moreover, so did the electorate. There is nothing new or surprising about any of this: people understand.

The passing of the Broadcasting Services Amendment (Online Services) Act 1999 apparently shows that prior to 30 June 1999 a majority of the members of the House of Representatives and the Senate may have understood that phone companies, courier services and the Post Office are only service providers, and hence not responsible for what their customers do, but they do not understand that Internet Service Providers (ISPs) are also only service providers. On the contrary, they have loaded ISPs with legal obligations that they would never dream of loading on to phone companies, courier services or postal services.

The first pointer to the peculiar treatment of ISPs is that they have been regulated under an amendment to the Broadcasting Services Act 1992 (BSA). 
When thinking about how to regulate the Internet, the Howard Government looked around for an appropriate model and decided that the Internet was a bit like narrowcasting $T V$, so that was how they regulated it - as a form of broadcasting.

There is a sense in which one can see how one might think that. The World Wide Web provides pictures on computer monitors. Computer monitors look a bit like television sets (and politicians understand TV, they are on it all the time and maybe, as busy people, they would like the Internet to be a cheap childminding service, you know, like TV, but not like pubs). There is some sort of mass transmission involved whereby many different users can be looking at the one picture, so it is a bit like broadcasting.

Except, of course, it is not. It makes even less sense to regulate ISPs via the model of the BSA giving enforcement responsibility to the Australian Broadcasting Authority than it would to regulate aircraft via amendments to the Navigation Act and give enforcement responsibility to Port Authorities.

ISPs are not broadcasters, and it is a completely inappropriate model to treat them as such. ISPs provide services used by other people to communicate. They are nothing like TV or radio stations. TV and radio stations have complete control over their own content, and it is perfectly reasonable to hold them responsible for it. ISPs (leaving aside multi-function companies) do not provide content, not even when they are content hosts, they provide facilities across which content can be accessed and posted by other people.

It would make far more sense to regulate ISPs under the Telecommunications Act. But, of course, if you did that it would immediately become obvious what a stupid exercise one was engaged in by holding Internet service providers responsible for how other people use their services. In electronic communication, the broadcasting model is the only way one can go and have any degree of plausibility whatsoever in holding ISPs responsible for content.

It is the people with websites, bulletin boards and chat groups that are doing the 'broadcasting'. Regulating them, however, is obviously difficult. They are much more numerous than ISPs and most of them are not even in Australia (this should have been a pretty broad hint about using the wrong regulatory model). Indeed, the actual content providers will just move off-shore, to North American and other ISPs. And treating everyone with a website as a 'broadcaster' under the Broadcasting Services Act is a patent nonsense (though there may be some ego gains in finding oneself being treated for regulation purposes as if one was Kerry Packer). So, again, to keep the broadcasting model going, one is driven back to treating the ISPs as the broadcasters they are not.

The Supplementary Explanatory Memorandum for the amendments to the original bill shows quite clearly the inherent problems involved in trying to squeeze a communication service into an inappropriate broadcasting model. Let us just take one statement from the Memorandum (page 4): 
An aim of this amendment is to make it clear that the Government does not intend that the regulation of Internet content should result in a degradation of network performance to a point where the Internet no longer meets the needs of the Australian community.

The first point is that nothing Australia does will substantially affect the Internet. The reference should have been 'to a point where access to the Internet no longer meets the needs of the Australian community'. This sort of mistake in expression implies a fundamental failure of understanding.

But the more substantive point is the phrase 'a degradation of network performance'. Now, we talk about radio and TV networks, but that is not quite the sort of network or network performance actually meant here, is it? This is a reference to a network like phones or post: you know, the sort of thing one gets access to at one's place of work, for example. Once again, the appropriate analogy is telecommunications, not broadcasting. So, one sentence manages to express the problems inherent in a misapplication of regulatory models.

The next amendment listed in the Supplementary Memorandum takes us further into regulatory blunderland. That section of the Memorandum starts:

Concerns have been raised that the Bill, taken in isolation, creates the impression that Internet service providers and Internet content hosts are to bear the prime burden in relation to offensive material rather than those who create and uphold such material.

My, my. We can see that perhaps this is indeed a bit of an odd impression to have created. Pity it is inherent in treating ISPs as broadcasters. So, the Memorandum continues:

To address this concern, Amendment (5) inserts a new explanatory statement at the beginning of the proposed Schedule 5 of the BSA. This statement puts the Bill in the context of a national scheme already agreed to by the Commonwealth, State and Territory Attorneys-General.

Well, I am sure that makes us all feel better. But, of course, if one focused on the people who actually provide the material everyone is allegedly so worried about, then, once again, the ISPs-as-broadcasters model looks just a tad ridiculous. Or, take another statement (page 10):

This provides that an Internet service provider will not be required to comply with a special-access prevention notice under subclause 44(1) in relation to a particular end-user of Internet content if access by the enduser is subject to a recognised alternative access-prevention arrangement that is applicable to the end-user.

Hope that is all clear. But, again, are we not confronted with the problems inherent in trying to shoe-horn a communications service into a broadcasting 
model? As for Internet-as-cheap-child-minding service, on page 6 we are informed that:

In making an instrument under subclause 3(1), the ABA [Australian Broadcasting Authority] will be required to have regard to the objective of protecting children from exposure to Internet content that is unsuitable for children ...

Yes, indeed, protecting children from naughty pictures, beyond parental supervision, is the declared point of the exercise. But a requirement on websitecreators for warning signs and, perhaps, credit card entry requirements (with an adult ID identifier) would do that at least as well as this crude and cumbersome exercise, without risking the viability of the industry or providers within it, or degrading Australia's access to the Internet. It would not, of course, provide a regime for controlling what was beyond the warning signs, and if you are trying to placate an anti-porn campaigner (Senator Harradine) who is on record as saying he thought the proposed scheme was in fact too loose, then simple practicality is presumably not enough.

And, of course, 'protecting children' is one of the best ways to have a go at people's freedoms. The only real bulwark against the excuse, after all, is a strong sense of parental responsibility. Otherwise, endless intrusions into otherwise adult activities are justifiable on the basis of 'oh, but we are only protecting children ...'

The peculiarity of treating websites, etc. as a form of 'broadcasting' is clearer and clearer the more one examines the issues. You don't need a credit card to watch a TV program or listen to a particular radio station, yet with commercial porn sites, that is usually exactly what you need. Not to mention going past the [warning] and [only enter if you are 18 or over] signs. Warning signs such as: by entering this site from the link below you certify that the following statements are true:

- I am at least 18 years of age

- I am requesting your materials for my own personal use in my private residence.

- I am not accessing this material to use against the site operator or any person whomsoever in any conceivable manner.

- I will not exhibit any material from your site to a minor and will carefully insure that no minor has access to it or any other person who might find such material personally offensive.

- The performers depicted on this site were all over 18 years of age at the time of the photography. The content is inappropriate for minors and extreme care should be taken to ensure that it is not viewed by any minor. 
Going further is a specific act, an entering into a marked domain, not a turning on of a TV or a radio. Use of the World Wide Web is much more like a huge series of accessible private conversations than conventional broadcasting. It is pub space, not public space.

Even more to the point, the sheer scale of operations makes a nonsense of the radio or TV broadcasting analogy. Even a small ISP may host thousands of 'webpages' on hundreds of sites. For a large ISP, we are talking millions. And each 'webpage' may involve several files, whose names may well give absolutely no indication whatsoever of their content. In the case of fully interactive sites, the number of 'webpages' producible from the input of the user may be infinite, with any pornographic content being entirely a result of the input of the user. A key feature of the Internet is its capacity to provide amazingly cheap self-expression - including artistic display for the general public. We are all potential 'broadcasters' on the Web, in a way that does not even begin to be true for radio and TV. With the Web, we are in the same situation as with phones or the post - if you pay, you can play. And ISPs are not, unlike publicans, engaged in providing behaviour-altering substances. Yet, they are now loaded with far greater statutory requirements than publicans.

The Commonwealth Government claims that the statutory requirement that regulatory action be 'technically feasible and commercially viable' means the regulations will not be excessively onerous for ISPs. When it was pointed out that commercial viability is something which varies from provider to provider, Minister Alston admitted that the effect would, therefore, be to result in different obligations being imposed on different providers (see Senate Hansard for 25 May 1999, page 5335). Apart from being a violation of procedural equality under the law, this indicates very starkly what an enforcement nightmare this illconceived regulatory system is. What one ISP will be legally required to do, because it can afford to do so, another ISP won't be, because it will not be able to afford to do so. What a nightmare for the $\mathrm{ABA}$ and the courts to deal with.

The Revised Explanatory Memorandum says (page 1):

The Government takes seriously its responsibility to provide an effective regime to address the publication of illegal and offensive material online, while ensuring that regulation does not place onerous or unjustifiable burdens on industry and inhibit the development of the online economy.

Well, they have already failed the unjustifiable criteria and we will have to see how things work in practice to see how onerous the burdens are. The Memorandum continues:

The proposed regulatory framework contained in the Bill strikes a balance between the needs and interests of the industry and wider community concerns in relation to material that is illegal or highly offensive, or may be harmful to children. 
All of which, of course, applies equally to postal and telephone services. Except, of course, we understand them. Continuing on,

The Government acknowledges that there are technical difficulties with blocking all illegal and offensive material that is hosted overseas but considers that where it is technically feasible to block material this should be done.

Yet again, is this not a pretty solid pointer that this is a telecommunications matter, not a broadcasting one? The text continues:

It is not acceptable to make no attempt at all on the basis that it may be difficult.

Which is a principle wide enough to justify almost any stupidity. Including, most certainly, this one. One is reminded of the classic Sir Humphrey Appleby quote 'if you are going to do this stupid, bloody thing, please don't do it in this stupid, bloody way'.

After a 10-month inquiry, on 17 May the Canadian broadcasting authority, the Canadian Radio-television and Telecommunications Commission, announced, that it would not be regulating the Internet in any way (see CRTC 1999). Canada understands the competitive pressures, difficulties involved and capacity of existing mechanisms to deal with content issues. It may even understand that ISPs are not broadcasters, in any useful sense. In the US, strong content regulation was struck down by the Supreme Court as a violation of the First Amendment's protection of free speech.

In Australia, the whole thing apparently had to be rushed through before 30 June 1999. Since the only public policy issue operating was anti-porn campaigner Senator Harradine no longer being a key swing vote, it is hard to avoid the conclusion that this botched system was a public policy pay-off, an attempt to secure Senator Harradine's vote. The Act certainly would not have passed after 30 June, since the Democrats, Greens and ALP all opposed it - not on the grounds that it was wrong to shield children from inappropriate material, but that this was a completely inappropriate way to go about it.

The Government would, and does, claim that 'the industry' was consulted. But anyone who has been around the public policy process knows how empty a process that can be. Who has access to Ministers and senior bureaucrats? Big providers. Their perspective on what is 'feasible' is entirely different from that of small operators. Moreover, they have vastly different interests regarding entry costs to the industry. It is very much in their interests to raise entry costs to the industry - something regulation can do very well - in order to restrict competition. Even a $\$ 40,000$ per ISP compliance cost would be enough to eliminate many ISPs. It may even be in big players' interests for a completely impractical regime to be implemented, on the basis that it will collapse eventually anyway and, in the meantime, eliminate much of their competition. 
Cyberspace is not public space and ISPs are not broadcasters. ISPs should be treated like phone companies, the Post Office and courier companies: they should be treated like the service providers they are, not the broadcasters they are not.

Applying a completely inappropriate regulatory model to an industry can only have one of three results. Either the regulations will rapidly become a deadletter, collapsing under their own unenforceability and inanity or else they will add greatly to the costs - in resources and time - of the operation of the industry or both will happen. Given that many ISPs are highly marginal enterprises, if the latter occurs one must expect a dramatic contraction in the number of providers and a weakening of Australia's connection to the Internet.

Australia has rapidly become one of the most Internet-enabled societies on the planet. This continues the long-standing pattern of Australia being an enthusiastic and rapid adopter of new communication technology, a natural response of a prosperous, technophile society to the tyranny of distance. Many in the industry are already saying that, thanks to this startlingly inappropriate regulatory regime, we have graduated from being a player in the global village the 'Net is creating, to being the global village idiot.

Well, we apparently can't tell the difference between what works like a TV station and what works like a phone company, can we?

It is certainly true that having restrictive Internet regulations puts us in some pretty unsavoury international company - such as China and various Middle Eastern tyrannies - even if the obsession is sex rather than politics. But, then that is just a different way of turning what, in a free society, is an activity for adults into something fit only for children.

Maybe some of our legislators could discuss it a bit more, next time they're having a few drinks down at the pub.

\section{References}

CRTC, News Release, May 17, 1999, 'CRTC Won't Regulate the Internet' at http://www.crtc.gc.ca/ENG/NEWS/RELEASES/1999/R990517e.htm

Hoyne, M. (1998), 'One for the Road: Liability of Servers of Alcohol', Law Institute Journal, 72(4):46-50.

I thank Mark Newton, from the Netizen ${ }^{\mathrm{TM}}$ politics list (politics@netizen.com.au) for his very enlightening comments explaining why cyberspace was like pub space, the unknown participant at the Melbourne anti-censorship seminar for his ironic 'well, it looks like a TV' comment, Phillip Walker and Kerry Corke for some legal points and Charles Dean and Jai Cornes for technical information. 